\title{
High Fibrinogen Plus Low Plasminogen Levels Predict Poor Post-Surgical Survival in Patients With Chronic Thromboembolic Pulmonary Hypertension
}

\author{
Manabu Horii, MD, PhD
}

C hronic thromboembolic pulmonary hypertension $(\mathrm{CTEPH})$ is a life-threatening condition involving pulmonary hypertension, hypoxemia, and right ventricular failure, characterized by arterial obstruction or obliteration by organized thrombus formation. The pathogenic mechanism of CTEPH is unknown. Blood coagulation disorders have been suggested as its etiology, and progression from acute to chronic pulmonary thromboembolism and antiphospholipid antibody syndrome have been identified as possible causes. However, many patients with CTEPH do not present with clotting abnormalities. CTEPH involves enhanced coagulation and reduced fibrinolytic potential. ${ }^{1-5}$ Decreased levels of thrombomodulin activity ${ }^{6}$ and increased levels of tissue plasminogen activator, plasminogen activator inhibitor-1, and coagulation factor $\mathrm{VIII}^{7}$ have been reported in anecdotal cases of CTEPH. It has recently been shown that high plasma fibrinogen and low plasminogen levels were associated with poor survival in patients with inoperable CTEPH. ${ }^{8}$

\begin{abstract}
Article p 970
Although the recent development of new pulmonary vasodilators and advancements in balloon pulmonary angioplasty ${ }^{9}$ have had a major effect on CTEPH treatment, pulmonary endarterectomy (PEA) still remains the standard treatment for central-type CTEPH. ${ }^{10-12}$ Increased thrombomodulin levels have been reported after PEA, ${ }^{6}$ but no previous studies have investigated the association between coagulation and fibrinolytic factors vs. survival outcomes of PEA-treated patients with CTEPH. The relationship between CTEPH and blood coagulation disorders is shown in the Table. ${ }^{13}$

In this issue of the Journal, Kato et $\mathrm{al}^{14}$ evaluate whether high fibrinogen plus low plasminogen levels predict poor postPEA survival in patients with CTEPH. Their study tested 2 hypotheses: (1) abnormalities in the coagulation and fibrinolytic system are associated with short-term (3-month) and long-term (1-year) survival after PEA, and (2) PEA causes
\end{abstract}

\begin{tabular}{|c|c|c|}
\hline Factors & Authors & Published year \\
\hline \multicolumn{3}{|l|}{ Risk factors of CTEPH } \\
\hline TF, CRP, TNF- $a, \mathrm{MCP}-1$ & Yang et al ${ }^{1}$ & 2015 \\
\hline Fibrinogen, NT-proBNP & Hennigs et $\mathrm{al}^{2}$ & 2014 \\
\hline ET-1 & Reesink et $\mathrm{al}^{3}$ & 2006 \\
\hline $\mathrm{t}-\mathrm{PA}, \mathrm{PAl}-1$ & Olman et $\mathrm{al}^{4}$ & 1992 \\
\hline Thrombin & Ogawa et $\mathrm{al}^{5}$ & 2013 \\
\hline TM & Sasaki et al ${ }^{6}$ & 2003 \\
\hline Clotting factor VIII, VWF & Bonderman et $\mathrm{al}^{7}$ & 2003 \\
\hline \multicolumn{3}{|c|}{ Prognostic prediction factors for patients with CTEPH } \\
\hline Dialysis, NYHA III/VI, PAP & Kato et al ${ }^{14}$ & 2016 \\
\hline Fibrinogen and plasminogen & Kato et $\mathrm{al}^{8}$ & 2014 \\
\hline Age & Ogino et al ${ }^{10}$ & 2006 \\
\hline PAP & Ishida et al ${ }^{11}$ & 2012 \\
\hline
\end{tabular}

BNP, B-type natriuretic peptide; CRP, C-reactive protein; CTEPH, chronic thromboembolic pulmonary hypertension; ET-1, endothelin 1; MCP-1, monocyte chemoattractant protein 1; NYHA, New York Heart Association; PAl-1, type 1 plasminogen activator inhibitor; PAP, pulmonary artery pressure; TF, tissue factor; TM, thrombomodulin; TNF- $a$, tumor necrosis factor- $a$; t-PA, tissue plasminogen activator; VWF, von Willebrand factor.

The opinions expressed in this article are not necessarily those of the editors or of the Japanese Circulation Society.

Received February 22, 2016; accepted February 23, 2016; released online March 4, 2016

Department of Cardiovascular Medicine, Nara City Hospital, Nara, Japan

Mailing address: Manabu Horii, MD, PhD, Department of Cardiovascular Medicine, Nara City Hospital, 1-50-1 Higashikidera, Nara 630-8305, Japan. E-mail: m-horii@nara-jadecom.jp

ISSN-1346-9843 doi:10.1253/circj.CJ-16-0195

All rights are reserved to the Japanese Circulation Society. For permissions, please e-mail: cj@j-circ.or.jp 
changes in the coagulation and fibrinolytic system that favor the survival of patients with CTEPH.

At 3 months after PEA, D-dimer, thrombin-antithrombin complex, coagulation factor VIII, fibrinogen, thrombomodulin, and plasmin- $\alpha 2$ plasmin inhibitor complex levels were significantly increased from baseline. Comparison of survivors and non-survivors showed that coagulation factor VIII concentration, pulmonary arterial blood pressure, and pulmonary vascular resistance were significantly higher in non-survivors.

At 1 year postoperatively, the partial pressure of oxygen and levels of thrombomodulin and plasminogen were significantly elevated compared with baseline, whereas pulmonary arterial blood pressure and pulmonary vascular resistance were significantly decreased from baseline. Patients with high fibrinogen plus low plasminogen levels accounted for $20 \%$ of the study population at baseline, with the proportion decreasing to $5 \%$ at 1 year postoperatively.

Among 20 long-term survivors, 5 had persistent pulmonary hypertension. No significant difference was observed in baseline coagulation or fibrinolytic parameters between patients with and without persistent pulmonary hypertension. Patients with persistent pulmonary hypertension had higher D-dimer and brain natriuretic peptide levels at 1 year postoperatively than those without. It was not clear whether pulmonary hypertension caused these changes or vice versa.

Disease-specific outcome analyses showed that age at diagnosis, high fibrinogen plus low plasminogen levels, pulmonary arterial blood pressure at 3 months postoperatively, and pulmonary vascular resistance at 3 months postoperatively were significantly associated with death.

A variety of coagulation and fibrinolytic factor abnormalities have been proposed as possible etiologies for CTEPH. Our results are the first to suggest that abnormal levels of coagulation and fibrinolytic factors may predict outcomes in patients with CTEPH undergoing PEA.

\section{Disclosures}

The author declares no conflicts of interest.

\section{References}

1. Yang M, Deng C, Wu D, Zhong Z, Lv X, Huang Z, et al. The role of mononuclear cell tissue factor and inflammatory cytokines in patients with chronic thromboembolic pulmonary hypertension. $J$ Thromb
Thrombolysis 2015 December 14, doi:10.1007/s11239-015-1323-2.

2. Hennigs JK, Baumann HJ, Lüneburg N, Quast G, Harbaum L, Heyckendof $\mathrm{J}$, et al. Fibrinogen plasma concentration is an independent marker of haemodynamic impairment in chronic thromboembolic pulmonary hypertension. Sci Rep 2014; 4: 4808.

3. Reesink HJ, Meijer RC, Lutter R, Boomsma F, Jansen HM, Kloek $\mathrm{JJ}$, et al. Hemodynamic and clinical correlates of endothelin-1 in chronic thromboembolic pulmonary hypertension. Circ J 2006; 70: $1058-1063$.

4. Olman MA, Marsh JJ, Lang IM, Moser KM, Binder BR, Schleef RR. Endogenous fibrinolytic system in chronic large-vessel thromboembolic pulmonary hypertension. Circulation 1992; 86: 1241-1248.

5. Ogawa A, Firth AL, Ariyasu S, Yamadori I, Matsubara H, Song S, et al. Thrombin-mediated activation of Akt signaling contributes to pulmonary vascular remodeling in pulmonary hypertension. Physiol Rep 2013; 1: e00190, doi:10.1002/phy2.190.

6. Sasaki F, Kyotani S, Nagaya N, Sato N, Oya H, Nakanishi N. Increase in thrombomodulin concentrations after pulmonary thromboendarterectomy in chronic thromboembolic pulmonary hypertension. Chest 2003; 124: 1305-1311.

7. Bonderman D, Turecek PL, Jakowitsch J, Weltermann A, Adlbrecht $\mathrm{C}$, Schneider B, et al. High prevalence of elevated clotting factor VIII in chronic thromboembolic pulmonary hypertension. Thromb Haemost 2003; 90: $372-376$.

8. Kato F, Tanabe N, Urushibara T, Kasai H, Takeuchi T, Sekine A, et al. Association of plasma fibrinogen and plasminogen with prognosis of inoperable chronic thromboembolic pulmonary hypertension. Circ J 2014; 78: 1754-1761.

9. Sugimura K, Fukumoto Y, Satoh K, Nochioka K, Miura Y, Aoki T, et al. Percutaneous transluminal pulmonary angioplasty markedly improves pulmonary hemodynamics and long-term prognosis in patients with chronic thromboembolic pulmonary hypertension. Circ J 2012; 76: 485-488.

10. Ogino H, Ando M, Matsuda H, Minatoya K, Sasaki H, Nakanishi N, et al. Japanese single-center experience of surgery for chronic thromboembolic pulmonary hypertension. Ann Thorac Surg 2006; 82: $630-636$.

11. Ishida K, Masuda M, Tanabe N, Matsumiya G, Tatsumi K, Nakajima N. Long-term outcome after pulmonary endarterectomy for chronic thromboembolic pulmonary hypertension. J Thorac Cardiovasc Surg 2012; 144: $321-326$.

12. Urushihara T, Tanabe N, Suda R, Kato F, Kasai H, Takeuchi T, et al. Effects of surgical and medical treatment on quality of life for patients with chronic thromboembolic pulmonary hypertension. Circ J 2015; 79: 2696-2702.

13. Delcroix M, Lang I, Pepke-Zaba J, Jansa P, D'Armini AM, Snijder $\mathrm{R}$, et al. Long-term outcome of patients with chronic thromboembolic pulmonary hypertension (CTEPH): Results from an international prospective registry. Circulation 2016; 133: 859-871.

14. Kato F, Tanabe N, Ishida K, Suda R, Sekine A, Nishimura R, et al. Coagulation-fibrinolysis system and postoperative outcomes of patients with chronic thromboembolic pulmonary hypertension. Circ J 2016; 80: 970-979. 